\title{
"Clickase" Single-Chain Nanoparticles: Effect of Intra-Chain Distribution of Catalytic Sites on Catalytic Activity
}

\author{
Isabel Asenjo-Sanz ${ }^{1}$, Tatiana Claros ${ }^{1}$, Edurne González ${ }^{1}$, Ester Verde-Sesto ${ }^{1}$ and José \\ A. Pomposo $1,2,3$ * \\ ${ }^{1}$ Centro de Física de Materiales (CSIC, UPV/EHU) and Materials Physics Center MPC, Paseo \\ Manuel de Lardizabal 5, E-20018 San Sebastián, Spain; misabel_asenjo@ehu.eus (I.A.-S.); \\ ntclaros001@ikasle.ehu.eus (T.C.); edurne.gonzalezg@ehu.eus (E.G.); mariaester.verde@ehu.eus \\ (E.V.-S.) \\ ${ }^{2}$ Departamento de Polímeros y Materiales Avanzados: Física, Química y Tecnología, Universidad \\ del País Vasco (UPV/EHU), Apartado 1072, E-20800 San Sebastián, Spain \\ ${ }^{3}$ IKERBASQUE - Basque Foundation for Science, Plaza Euskadi 5, E-48009 Bilbao, Spain \\ * Correspondence: Josetxo.pomposo@ehu.eus
}

\begin{abstract}
Clickase" single-chain nanoparticles (Ck-SCNPs) are folded, enzyme-mimetic unimolecular polymeric nano-objects containing copper $(\mathrm{Cu})$ ions able to catalyze the azide-alkyne Huisgen cycloaddition reaction in water and/or selected organic solvents, often in the presence of a reductant. Herein, we investigate the effect of morphology on catalytic activity of Ck-SCNPs synthesized by means of two different routes. An amphiphilic random copolymer composed of oligo(ethylene glycol) methyl ether methyl methacrylate (OEGMA) and 2-acetoacetoxy ethyl methacrylate (AEMA) units was used as precursor of these Ck-SCNPs. Folding was promoted through metal complexation between $\mathrm{Cu}(\mathrm{II})$ ions and $\beta$-ketoester-containing AEMA moieties. The first route resulted in Ck-SCNPs1 containing $\mathrm{Cu}$ ions homogeneously distributed within each nanoparticle, whereas the second one promoted intra-chain clustering of $\mathrm{Cu}$ ions inside Ck-SCNPs2. A model fluorogenic "click" reaction between 9-(azidomethyl)anthracene and phenylacetylene, which was catalyzed either by Ck-SCNPs1 or Ck-SCNPs2, was used to unravel the effect of morphology on catalytic activity. This work paves the way to improve the catalytic activity of metallo-folded SCNPs through control of the intra-chain distribution of catalytic sites.
\end{abstract}

Keywords: folding; single-chain nanoparticles; catalysis; click chemistry

\section{Introduction}

Folding of individual synthetic polymer chains at high dilution via intra-chain interactions gives to so-called single-chain nanoparticles (SCNPs) [1]. A great variety of intra-chain interactions have been used to construct SCNPs covering form covalent bonds to non-covalent and dynamic covalent interactions [2-17]. Interestingly enough, the folded conformation of SCNPs produces locally compact domains (i.e., local pockets) to which entrapment of substances of potential interest can be carried out (e.g., drugs for subsequent controlled delivery, metal ions for catalysis, luminophores for sensing) [18-24]. The outstanding opportunities of SCNPs for developing a new generation of enzyme-mimetic catalysts have been recently reviewed $[6,25,26]$. In this sense, the nature of the precursor polymer and synthesis conditions were found to have a profound effect on the conformation of SCNPs in solution [1]. Hence, SCNPs synthesized from precursors in good solvent at high dilution result in sparse, open conformations possessing multiple internal nanodomains $[27,28]$. Conversely, synthesis of SCNPs in water from appropriate 
amphiphilic random copolymer precursors gives to a core-shell morphology with an internal, larger hydrophobic nanodomain [11,18].

On one hand, a variety of sparse SCNPs endowed with catalytic properties have been reported [29-43]. Hence, SCNPs showing reductase- and polymerase-like properties were developed by our team based on the entrapment of $\mathrm{B}\left(\mathrm{C}_{6} \mathrm{~F}_{5}\right)_{3}$ into the SCNP nanodomains [29]. $\mathrm{Rh}(\mathrm{I})$-containing SCNPs displaying selective homocoupling to give biphenyl under reaction conditions favorable to cross-coupling were reported by Lemcoff et al. during the reaction of 4-nitrobenzaldehyde and phenyl boronic acid [30]. Our team developed $\mathrm{Cu}$ (II)containing SCNPs showing enzyme-mimetic substrate selectivity in oxidative coupling of mixtures of terminal alkynes [31]. Sparse SCNPs containing Pd- and Pt-complexes were synthesized by Barner-Kowollik and coworkers and employed as a novel type of catalyst for the Sonogashira coupling of terminal alkynes and aryl halides [32] and as homogeneous yet recyclable catalysts for the amination of allyl alcohol [33], respectively. In a recent work by this team, heterobimetallic $\mathrm{Eu}(\mathrm{III}) / \mathrm{Pt}(\mathrm{II})$ sparse SCNPs have been synthesized entailing both catalytic and luminescent properties [34]. He et al. produced Ni-containing sparse SCNPs with high activity and selectivity towards the photoreduction of $\mathrm{CO}_{2}$ to $\mathrm{CO}$ in organic solvents [35]. Moreover, Hübner and colleagues [36] synthesized more than 30 different metal-containing SCNPs (including $\mathrm{Cu}^{2+}, \mathrm{Co}^{2+}, \mathrm{Ni}^{2+}, \mathrm{Zn}^{2+}, \mathrm{Fe}^{2+}, \mathrm{Mn}^{2+}$ and $\mathrm{Pd}^{2+}$ as metal ions). Interestingly, $\mathrm{Pd}^{2+}$-containing SCNPs were found to provide a significant improvement in the Suzuki-Miyaura reaction when compared to traditional catalytic systems. Highly efficient thermoresponsive organocatalytic SCNPs towards tetrahydropyranilation of methanol were reported by Rumyantsev and colleagues [37]. Recently, a variety of N-heterocyclic carbene-based SCNPs have been synthesized by Taton and colleagues and employed as advanced catalysts for the benzoin condensation reaction [38,39]. More recently, Yan and coworkers have reported $\mathrm{CO}_{2}$-folded SCNPs that can function as recyclable, intensified carboxylase mimics [40]. An efficient homogeneous photoredox catalyst based on SCNPs bearing both photocatalyst and electron-relay functions has been demonstrated by Elacqua et al. [41]. $\mathrm{Pt}(0)$-containing SCNPs exhibiting better catalytic properties for the reduction of $p$-nitrophenol to $p$-aminophenol than normal polymer carried platinum particles have been synthesized by $\mathrm{Pu}$ and coworkers [42]. $\mathrm{Cu}(\mathrm{I})$-containing SCNPs with better catalytic performance than cuprous iodide for the click reaction of phenyl acetylene and sodium azide have been reported also by this team [43].

On the other hand, a diversity of works reported catalytic systems based on core-shell SCNPs [44-63]. Hence, Palmans, Meijer and colleagues pioneered the synthesis of $\mathrm{Ru}(\mathrm{II})$ containing catalytic SCNPs with a hydrophobic core/ hydrophilic shell morphology in water [44] that were used for the transfer hydrogenation reaction of ketones and oxidation of secondary alcohols into the corresponding ketones [45]. Subsequent works by these authors reported L-proline-containing core/shell SCNPs as organocatalysts for aldol reactions $[46,47]$ and $\mathrm{Cu}(\mathrm{I})$ - and $\mathrm{Pd}(\mathrm{II})$-containing core/shell SCNPs as catalysts for azidealkyne cycloaddition and depropargylation reactions, respectively [48]. The $\mathrm{Cu}(\mathrm{I})$ - and Pd(II)-containing core/shell SCNPs were subsequently screened in vivo and studied in cellular environments for the carbamate cleavage reaction of rhodamine-based substrates [49]. Our team developed $\mathrm{Cu}(\mathrm{II})$ - and $\mathrm{Fe}(\mathrm{II})$-containing core/shell SCNPs with metalloenzyme mimicking characteristics for the controlled synthesis of water-soluble polymers [50] and intrinsically conducting polymers such as PEDOT [51], respectively. Zimmerman et al. developed a variety of Cu-containing core/shell SCNPs ("clickases") able to catalyze the azide-alkyne cycloaddition reaction at low $\mathrm{Cu}$ content and even in biological, intracellular media [52,53] as well as over protein and cell surfaces [54]. Even, nonmembrane permeable SCNP that can efficiently catalyze the click reaction extracellularly for in situ anticancer drug synthesis and screening were synthesized by this team [55]. Moreover, Ru-containing core/shell SCNPs developed by this group were found to bind and deliver enzymes across cell membranes for concurrent and tandem catalysis in cells [56]. The importance of the secondary coordination sphere of catalytic $\mathrm{Cu}$ - 
containing core-shell SCNPs has been highlighted by He and coworkers in a series of papers $[57,58]$. Also, fine tuning of SCNP morphology and activity has been demonstrated by Tan and coworkers using entrapped chiral salen-Ti(IV) and chiral oxazoline-Ti(IV) complexes for asymmetric sulfoxidation in water [59,60]. Remarkably, a series of catalytically active core-shell SCNPs based on N-heterocyclic carbenes (NHCs) have been recently developed by Taton and coworkers [61-63].

In spite of these advances, investigations about how the intra-chain distribution of catalytic sites affects the catalytic activity of SCNPs are very scarce. We envisioned that controlling the spatial distribution of catalytic sites in metallo-folded SCNPs should be critical for the rational design of improved catalytic soft nano-objects. Based on the use of amphiphilic random copolymers and two different SCNP synthesis procedures involving selective or nonselective solvents, we reported previously a pathway for tuning the internal structure of metallo-folded SCNPs [64]. The first SCNP synthesis procedure involved the conventional synthesis in good solvent (method 1$)$. The second one was based on transfer, after SCNP formation, from selective to good solvent conditions (method 2). By combining size exclusion chromatography (SEC) with triple detection, small-angle Xray scattering (SAXS) and molecular dynamics (MD) computer simulations we unraveled the SCNP size, sparse morphology in good solvent and spatial distribution of catalytic sizes for Cu-containing SCNPs ("clickase" SCNPs, Ck-SCNPs) synthesized by method 1 (Ck-SCNPs1) and method 2 (Ck-SCNPs2). Interestingly, we observed a homogeneous distribution of catalytic sites in the case of Ck-SCNPs1 but the presence of clusters of catalytic sites in the case of Ck-SCNPs2 in good solvent [64]. However, we did not investigate at that time the effect of these very different distributions of active sites on the catalytic activity of Ck-SCNPs1 and Ck-SCNPs2. Herein we report the results obtained from a model fluorogenic "click" reaction between 9-(azidomethyl)anthracene and phenylacetylene, which was catalyzed either by Ck-SCNPs1 or Ck-SCNPs2. Additionally, we investigate the effect of the nature of the solvent in which this model "click" reaction is carried out. The results obtained are of great interest for further advance the field of enzyme-mimetic SCNPs.

\section{Experimental Section}

\subsection{Materials}

Oligo(ethylene glycol) methyl ether methacrylate (OEGMA, $\left.\mathrm{M}_{\mathrm{n}} \sim 300 \mathrm{Da}\right), 2$ acetoacetoxy ethyl methacrylate (AEMA) (95\%), 2,2-azobis(2-methylpropionitrile) (AIBN) $(\geq 98 \%)$, copper (II) acetate $(\mathrm{Cu}(\mathrm{OAc}) 2)(98 \%)$, phenylacetylene $(\mathbf{1})(98 \%)$, sodium azide ( $99 \%$ ), sodium ascorbate (NaAsc) $(99 \%)$, copper(II) sulfate $\left(\mathrm{CuSO}_{4}\right)$ (anhydrous, powder, $\geq 99.99 \%$ trace metals basis), 1,4-dioxane (anhydrous, $99.8 \%$ ), hexane (anhydrous, $95 \%$ ), acetonitrile $\left(\mathrm{CH}_{3} \mathrm{CN}\right)(99.9 \%)$, dimethyl sulfoxide (DMSO) (anhydrous, $299.9 \%$ ) and deuterated chloroform $\left(\mathrm{CDCl}_{3}\right)(99.96$ atom \% D, containing $0.03 \%(\mathrm{v} / \mathrm{v})$ tetramethylsilane, TMS) were purchased from Aldrich and used, unless specified, as received. 4Cyanopentanoic acid dithiobenzoate (CPADB) ( $\mathrm{min} 97 \%$ ) was purchased from Strem Chemicals. Methanol (MeOH) (synthesis grade) and tetrahydrofuran (THF) (GPC grade) were supplied by Scharlab. 9-(Chloromethyl)anthracene (2) (98+\%) was purchased from Acros Organics. Deionized water obtained from a Thermo Scientific apparatus (Barnstead TII Pure Water System) was employed in this work. OEGMA and AEMA were purified by passing through basic alumina. AIBN was recrystallized from methanol.

\subsection{Techniques}

\subsubsection{Size-Exclusion Chromatography (SEC) with Triple Detection (DRI / MALLS / VI)}

SEC measurements with triple detection (differential refractive index (DRI), multiangle laser light scattering (MALLS) and viscosimetric (VI) detectors) were performed at $30{ }^{\circ} \mathrm{C}$ on an Agilent 1200 system equipped with PLgel $10 \mu \mathrm{m}$ Guard and PLgel $10 \mu \mathrm{m}$ 
MIXED-B LS columns, a differential refractive index (DRI) detector (Optilab Rex, Wyatt), a multi-angle laser light scattering (MALLS) detector (MiniDawn Treos, Wyatt) and a viscosimetric (VI) detector (ViscoStar-II, Wyatt). THF was used as eluent at a flow rate of $1 \mathrm{~mL} / \mathrm{min}$. Data analysis was performed with ASTRA Software (version 6.1) from Wyatt, by using $\mathrm{dn} / \mathrm{dc}=0.115[64]$.

\subsection{2. ${ }^{1} \mathrm{H}$ Nuclear Magnetic Resonance ( ${ }^{1} \mathrm{H}$ NMR)}

${ }^{1} \mathrm{H}$ NMR spectra were recorded at room temperature on a Bruker spectrometer operating at $400 \mathrm{MHz}$ using $\mathrm{CDCl}_{3}$ as solvent.

\subsubsection{Dynamic Light Scattering (DLS)}

DLS measurements were carried out at room temperature on a Malvern Zetasizer Nano ZS apparatus.

\subsubsection{Differential Scanning Calorimetry (DSC)}

DSC measurements were carried out on 5-10 mg of sample using a Q2000 TA Instrument. A liquid nitrogen cooling system (LCNS) was used with a $25 \mathrm{~mL} / \mathrm{min}$ helium flow rate. Measurements were performed using hermetic aluminum pans from $-150{ }^{\circ} \mathrm{C}$ to $100{ }^{\circ} \mathrm{C}$, at a scanning rate of $10^{\circ} \mathrm{C} / \mathrm{min}$.

\subsubsection{Thermal Gravimetric Analysis (TGA)}

TGA measurements were performed in a Q500-TA Instruments apparatus at a heating rate of $10{ }^{\circ} \mathrm{C} / \mathrm{min}$ under nitrogen atmosphere from room temperature to $800^{\circ} \mathrm{C}$.

\subsubsection{Fluorescence Spectroscopy (FS)}

Photoluminiscence spectra were recorded at room temperature on an Agilent Cary Eclipse spectrometer at an excitation wavelength of $370 \mathrm{~nm}$.

\subsection{Methods}

2.3.1. Synthesis of the Amphiphilic Poly(OEGMA-co-AEMA) Random Copolymer (P1)

Amphiphilic poly(OEGMA-co-AEMA) random copolymer P1 containing $17 \mathrm{~mol} \%$ of AEMA units as determined by ${ }^{1} \mathrm{H}$ NMR spectroscopy (i.e., $17 \mathrm{~mol} \%$ of $\beta$-ketoester moieties as ligands for $\mathrm{Cu}$ (II) ions) was prepared following a method previously reported by our group [64].

\subsubsection{Synthesis of "Clickase" SCNPs by Method 1 (Ck-SCNPs1)}

In a typical reaction, P1 $(100 \mathrm{mg}, 0.06 \mathrm{mmol})$ was dissolved in THF $(90 \mathrm{ml})$ at room temperature. Then, a solution of $\mathrm{Cu}(\mathrm{OAc})_{2}(6 \mathrm{mg}, 0.03 \mathrm{mmol} \mathrm{Cu})$ in $10 \mathrm{ml}$ of THF was added, and the mixture was maintained under stirring for $24 \mathrm{~h}$. After reaction completion to give Ck-SCNPs1, the system was concentrated and precipitated in hexane (twice). Finally, Ck-SCNPs1 were dried in a vacuum oven at r.t. under dynamic vacuum [64].

\subsubsection{Synthesis of "Clickase" SCNPs by Method 2 (Ck-SCNPs2)}

In a typical reaction, $\mathbf{P 1}(100 \mathrm{mg}, 0.06 \mathrm{mmol})$ was dissolved in deionized water $(90 \mathrm{ml})$ at room temperature. Then, a solution of $\mathrm{Cu}(\mathrm{OAc})_{2}(6 \mathrm{mg}, 0.03 \mathrm{mmol} \mathrm{Cu})$ in $10 \mathrm{ml}$ of 
deionized water was added, and the mixture was maintained under stirring for $24 \mathrm{~h}$. After reaction completion, the system was freeze-dried.

\subsubsection{Synthesis of 9-(Azidomethyl)anthracene (3)}

9-(Azidomethyl)anthracene (3) was prepared from 9-(chloromethyl)anthracene (2) following a method reported in the literature [65] (see Scheme 1).<smiles>ClCc1c2ccccc2cc2ccccc12</smiles>

2<smiles>CC(C)NNCc1c2ccccc2cc2ccccc12</smiles>

3

Scheme 1. Synthesis of 3 from 2 [65].

\subsubsection{Synthesis of 3-(Anthracen-9-ylmethyl)-5-phenyltriazole (4)}

The fluorescent compound 3-(anthracen-9-ylmethyl)-5-phenyltriazole (4) [66] was synthesized from non-fluorescent 9-(azidomethyl)anthracene (3) and phenylacetylene (1) via azide-alkyne cycloaddition reaction in the presence of sodium ascorbate (NaAsc) as reducing agent and Ck-SCNPs1 or Ck-SCNPs2 as catalysts (see Scheme 2). In a typical procedure, $\mathbf{1}$ ( $3.9 \mathrm{mg}, 0.038 \mathrm{mmol}), \mathbf{3}(8.9 \mathrm{mg}, 0.038 \mathrm{mmol}), \mathbf{C k}-\mathrm{SCNPs} 1(20 \mathrm{mg}, 0.006 \mathrm{mmol})$ and sodium ascorbate $(1.75 \mathrm{mg}, 0.01 \mathrm{mmol})$ were added to $10 \mathrm{~mL}$ of solvent at r.t. and the resulting fluorogenic "click" reaction was monitored directly via FS. Either a mixture of THF and water (3:1) or neat DMSO were used as solvents. Control reactions were performed using $\mathrm{CuSO}_{4}$ as catalyst instead of Ck-SCNPs1 or Ck-SCNPs2.<smiles>N#Cc1c2ccccc2cc2ccccc12</smiles>

3

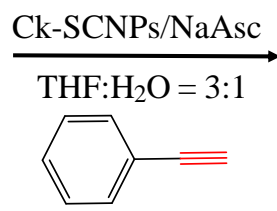

1

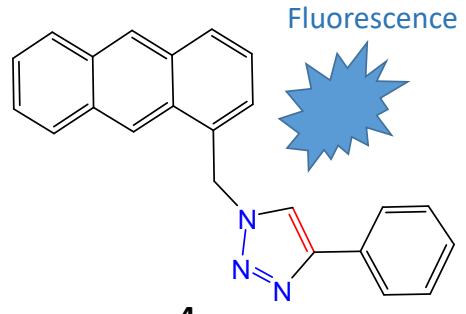

4

Scheme 2. Fluorogenic "click" reaction between 3 and $\mathbf{1}$ in aqueous THF [66].

\section{Results and Discussion}

The aim of this work is to determine how the intra-chain distribution of catalytic sites affects the catalytic activity of metallo-folded SCNPs. As precursor of the SCNPs, we synthesized an amphiphilic random copolymer denoted as P1 decorated with $\beta$-ketoester units via RAFT polymerization of MMA and AEMA, following a procedure previously optimized by our group [64]. SEC measurements with triple detection of P1 revealed a weight average molecular weight $\left(M_{\mathrm{w}}\right)$ of $72.1 \mathrm{kDa}$ and a very narrow dispersity of $\boxminus=$ 1.02. P1 contained $17 \mathrm{~mol} \%$ of $\beta$-ketoester moieties as determined by ${ }^{1} \mathrm{H}$ NMR spectroscopy. It is well-known that $\beta$-ketoester groups are efficient ligands for $\mathrm{Cu}$ (II) ions to give $\mathrm{Cu}(\beta \text {-ketoester })_{2}$ complexes. When complexation takes place within an individual polymer chain decorated with $\beta$-ketoester units at high dilution in a good solvent, metallofolded SCNPs are obtained (see Figure 1, method 1) [31]. As reported by Zimmerman and 


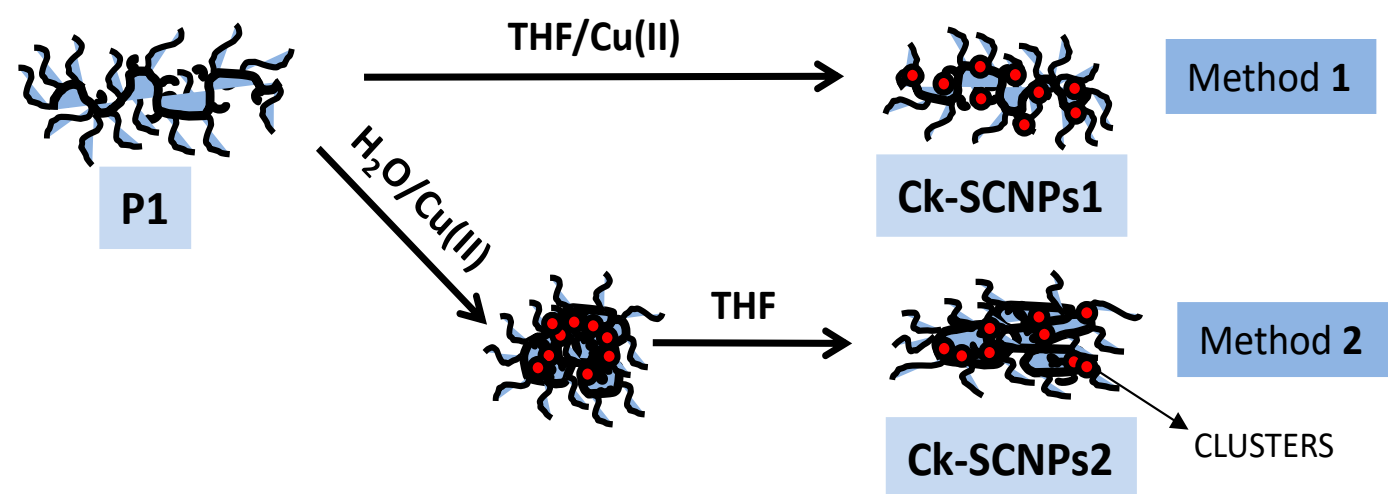

Figure 1. Schematic illustration of the synthesis of "clickase" single-chain nanoparticles (Ck-SCNPs) by two methods, giving rise to a relatively uniform distribution of catalytic sites in the case of CkSCNPs1 (method 1) or to the presence of clusters of catalytic sites in the case of Ck-SCNPs2 (method 2). Catalytic sites involving $\mathrm{Cu}$ ions are depicted in red.

coworkers [54], $\mathrm{Cu}$ (II)-containing SCNPs under reducing conditions can function as highly efficient catalyst of the azide-alkyne Huisgen cycloaddition reaction (i.e., "ckickase" SCNPs, Ck-SCNPs). Herein we denote as Ck-SCNPs1 the Cu-containing SCNPs obtained from P1 via method 1 (see Figure 1 and section 2.3). From our previous study combining SEC, SAXS and MD simulations [64], a uniform distribution of $\mathrm{Cu}$ catalytic sites is expected for metallo-folded SCNPs obtained using method 1. Conversely, the presence of clusters of $\mathrm{Cu}$ catalytic sites is expected in metallo-folded SCNPs synthesized via method 2 when dissolved in a non-selective, good solvent (e.g., THF) (see Figure 1, method 2). We denote the Cu-containing SCNPs obtained from P1 via method 2 as Ck-SCNPs2 (see Figure 1 and section 2.3).

Characterization of Ck-SCNPs1 and Ck-SCNPs2 by means of SEC measurements in THF revealed an increase in retention time (i.e., reduction of hydrodynamic size) when compared to precursor P1, as illustrated in Figure 2A,B. The reduction in hydrodynamic
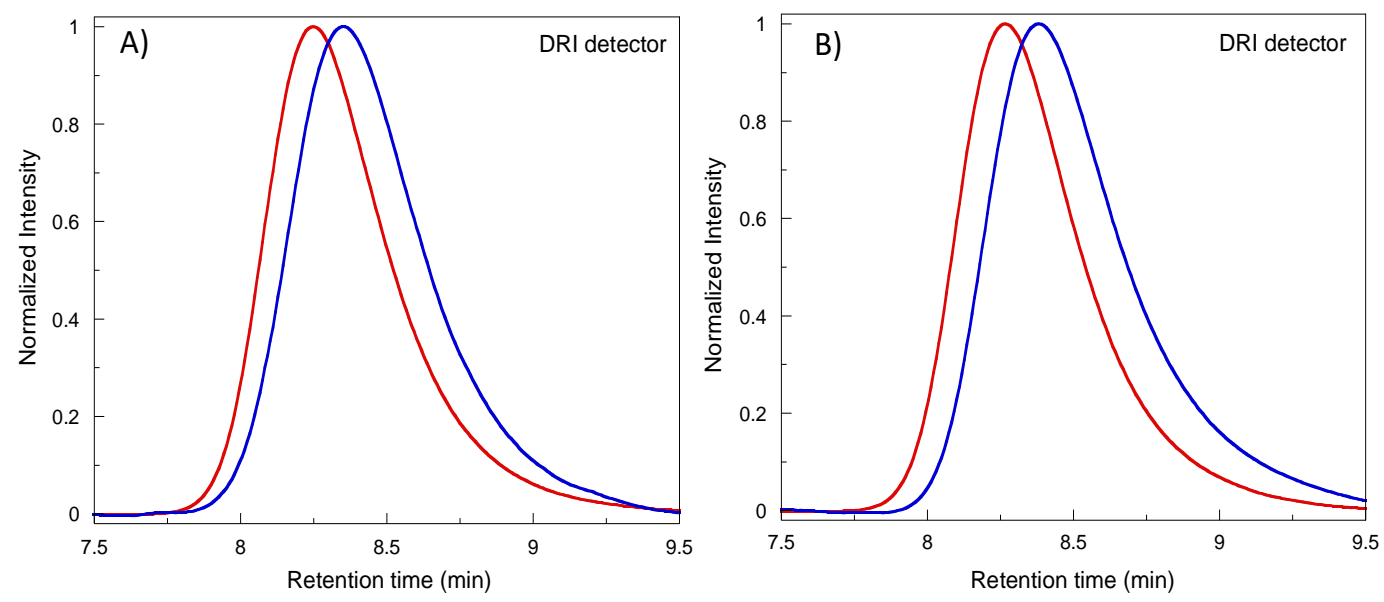

Figure 2. A) SEC traces of Ck-SCNPs1 (blue) and P1 (red). B) SEC/DRI traces of Ck-SCNPs2 (blue) and P1 (red).

size was a direct consequence of the formation of intra-chain $\mathrm{Cu}(\beta \text {-ketoester })_{2}$ complexes in both Ck-SCNPs1 and Ck-SCNPs2. As expected, we found no significant changes within the experimental error of the technique- in actual $M_{w}$ data obtained from the MALS detector of Ck-SCNPs1 $\left(M_{\mathrm{w}}=68.0 \mathrm{kDa}\right)$ and Ck-SCNPs2 $\left(M_{\mathrm{w}}=70.0 \mathrm{kDa}\right)$ when compared to that of $\mathbf{P 1}\left(M_{\mathrm{w}}=72.1 \mathrm{kDa}\right)$. As revealed by TGA measurements (Figure 3A,B), the amount 

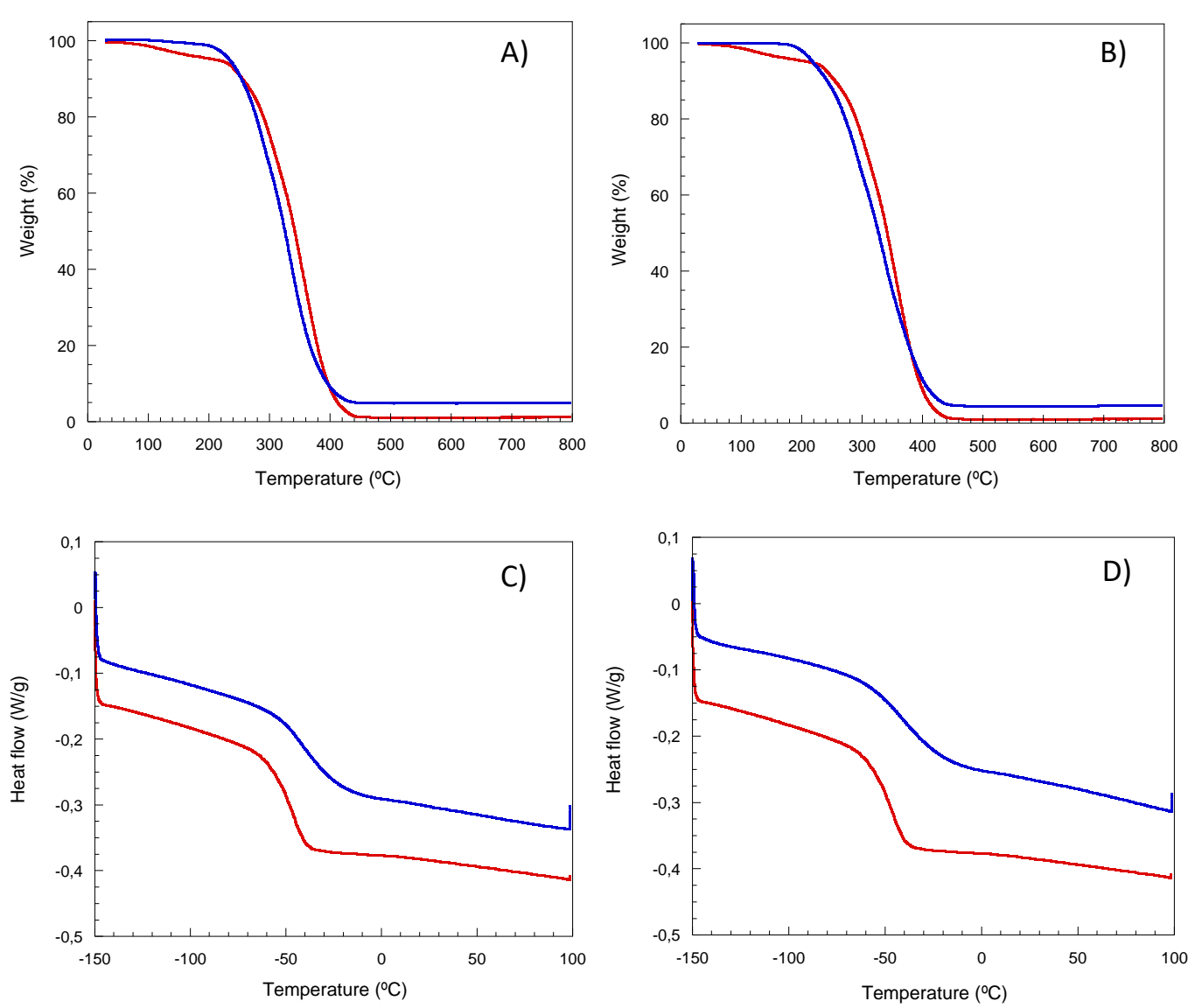

Figure 3. A) TGA traces of Ck-SCNPs1 (blue) and P1 (red). B) TGA traces of Ck-SCNPs2 (blue) and P1 (red). C) DSC traces of Ck-SCNPs1 (blue) and P1 (red). D) DSC traces of Ck-SCNPs2 (blue) and P1 (red).

of $\mathrm{Cu}$ incorporated into Ck-SCNPs1 and Ck-SCNPs2 was very similar, although as stated previously the distribution of catalytic sizes would be rather different in Ck-SCNPs2 when compared to Ck-SCNPs1 due to the presence of clusters in the former. TGA results obtained following the method reported in ref. [31] showed almost complete formation of the theoretical amount of $\mathrm{Cu}(\beta$-ketoester) 2 complexes in both Ck-SCNPs1 (>99\%) and CkSCNPs2 (>99\%). DSC measurements (Figure 3C,D) revealed a similar increase in glass transition temperature $\left(T_{g}\right)$ for SCNPs1 $\left(T_{g}=-41.3^{\circ} \mathrm{C}\right)$ and Ck-SCNPs2 $\left(T_{g}=-41.5^{\circ} \mathrm{C}\right)$ when compared to that of $\mathbf{P 1}\left(T_{\mathrm{g}}=-47.6^{\circ} \mathrm{C}\right)$. The increase in $T_{\mathrm{g}}$ is also a signature of the efficient formation of intra-chain $\mathrm{Cu}(\beta \text {-ketoester })_{2}$ complexes that restrict the mobility of the AEMA chain segments involved and, probably, also that of near-neighbor segments. Consequently, the hydrodynamic size, content of $\mathrm{Cu}(\beta \text {-ketoester })_{2}$ complexes and thermal behavior of Ck-SCNPs1 and Ck-SCNPs2 was very similar even having a different internal distribution of $\mathrm{Cu}$ catalytic sites.

Subsequently, we investigated the catalytic activity of Ck-SCNPs1 and Ck-SCNPs2 using a model fluorogenic "click" reaction between non-fluorescent phenylacetylene (1) and 9-(azidomethyl)anthracene (3) to give the fluorescent compound 3-(anthracen-9ylmethyl)-5-phenyltriazole (4) (see Scheme 2). Two different reaction media were selected to guarantee the solubility of reagents $\mathbf{1}$ and 3 as well as the product 4: aqueous THF (a mixture of THF and $\mathrm{H}_{2} \mathrm{O}$ at a volume ratio 3:1) and neat DMSO. It is worth mentioning that Ck-SCNPs1 and Ck-SCNPs2 are completely soluble in both aqueous THF and DMSO without the presence of aggregates, as determined by DLS measurements (see Figure 4). Control reactions for comparison were performed by replacing Ck-SCNPs1 and CkSCNPs2 by $\mathrm{CuSO}_{4}$ as catalyst. Figure $5 \mathrm{~A}$ illustrates the fluorescence observed from the 

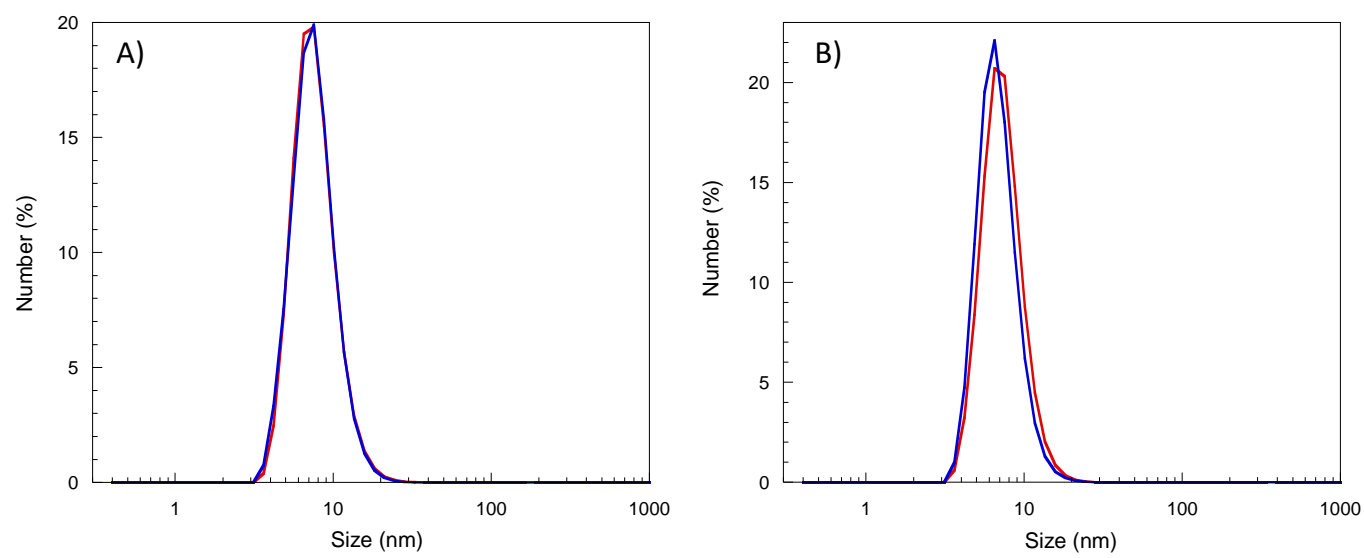

Figure 4. A) DLS traces of Ck-SCNPs1 (blue) and Ck-SCNPs2 (red) in a mixture of THF and $\mathrm{H}_{2} \mathrm{O}$ at a volume ratio 3:1 at a concentration of $1 \mathrm{mg} / \mathrm{mL}$. B) DLS traces of Ck-SCNPs1 (blue) and CkSCNPs2 (red) in neat DMSO at a concentration of $1 \mathrm{mg} / \mathrm{mL}$.
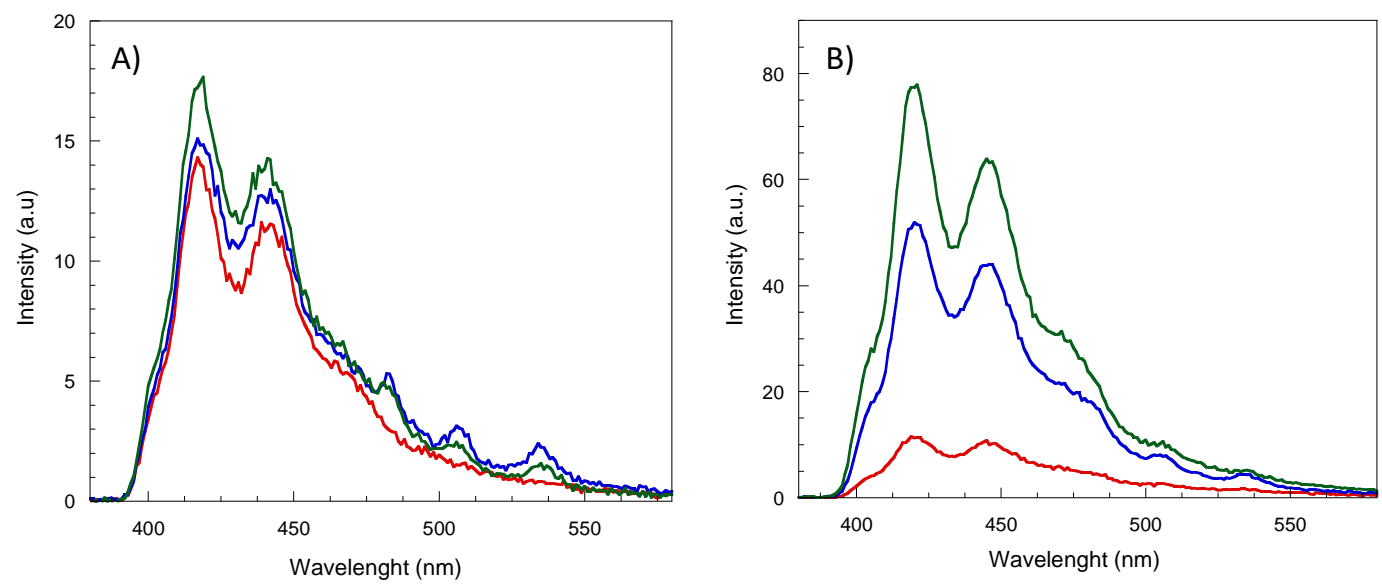

Figure 5. Comparison of the catalytic activity of Ck-SCNPs1 (blue trace), Ck-SCNPs2 (green trace) and $\mathrm{CuSO}_{4}$ (red trace) as catalysts of the fluorogenic "click" reaction between non-fluorescent $\mathbf{1}$ and 3 to give the fluorescent compound 4 in: A) aqueous THF after 1 h of reaction time, and B) neat DMSO after $6 \mathrm{~h}$ of reaction time, as recorded through fluorescence spectroscopy.

product of reaction, 4 , after $1 \mathrm{~h}$ of reaction time by using Ck-SCNPs1 (blue trace), CkSCNPs2 (green trace) or $\mathrm{CuSO}_{4}$ (red trace) as catalysts of the fluorogenic "click" reaction between $\mathbf{1}$ and 3 in aqueous THF (Figure 5A). Figure 5B illustrates the results obtained in DMSO at longer reaction time. In this sense, the fluorogenic "click" reaction was found to be faster in aqueous THF than in DMSO and Ck-SCNPs2 being more efficient than CkSCNPs1 and $\mathrm{CuSO}_{4}$ in both solvents. The high reproducibility of the results and the high sensitivity of the fluorescence spectroscopy technique allowed us to perform such a reliable comparison between different catalytic systems. Remarkably, the difference in catalytic activity observed (Ck-SCNPs2 $>$ Ck-SCNPs1 $>\mathrm{CuSO}_{4}$ ) was more notorious in DMSO than in aqueous THF. The slower reaction rate in DMSO can be attributed -to a large extent- to the oxidant power of this solvent [67] that oxidizes a certain amount of $\mathrm{Cu}(\mathrm{I})$ ions generated by $\mathrm{NaAsc}$ to $\mathrm{Cu}$ (II) ions, the latter being inactive for the "click" reaction. Interestingly enough, the presence of cluster of $\mathrm{Cu}$ ions in the case of Ck-SCNPs2 was found beneficial for improving the stability and effectiveness of the "clickase" SCNPs 
under the deactivating, oxidative nature of the DMSO solvent. The above experiments with a model fluorogenic "click" reaction and different reaction media provide solid support that the intra-chain distribution of catalytic sites has an important effect on the catalytic activity of "clickase" SCNPs, especially in solvents with significant oxidative nature like DMSO [67].

\section{Conclusions}

We investigate the effect of intra-chain distribution of catalytic sites on catalytic activity of Ck-SCNPs as folded, enzyme-mimetic unimolecular polymeric nano-objects containing $\mathrm{Cu}$ ions able to catalyze the azide-alkyne Huisgen cycloaddition reaction under appropriate reaction conditions. By using an amphiphilic random copolymer composed of $83 \mathrm{~mol} \%$ of OEGMA units and $17 \mathrm{~mol} \%$ of $\beta$-ketoester-containing AEMA units, we synthesize Ck-SCNPs by two different methods. The first one results in Ck-SCNPs1 containing $\mathrm{Cu}$ ions homogeneously distributed within each nanoparticle in the form of individual $\mathrm{Cu}(\beta \text {-ketoester })_{2}$ complexes, whereas the second method promotes intra-chain clustering of $\mathrm{Cu}(\beta \text {-ketoester })_{2}$ complexes inside Ck-SCNPs2. To unravel the effect of morphology on catalytic activity, we have evaluated the efficiency of Ck-SCNPs1 and CkSCNPs2 in a model fluorogenic "click" reaction between non-fluorescent 9(azidomethyl)anthracene and phenylacetylene to give the fluorescent compound 3(anthracen-9-ylmethyl)-5-phenyltriazole. Fluorescence spectroscopy experiments allowed us to determine the catalytic efficiency of Ck-SCNPs1 and Ck-SCNPs2 when compared to a classical catalyst such as $\mathrm{CuSO}_{4}$. Using aqueous THF or neat DMSO in the presence of NaAsc as reducing agent, the catalytic activity was found to follow the order: Ck-SCNPs2 > Ck-SCNPs1 $>\mathrm{CuSO}_{4}$. The fluorogenic "click" reaction was faster in aqueous THF than in DMSO -a solvent that promotes the oxidation of $\mathrm{Cu}(\mathrm{I})$ to $\mathrm{Cu}(\mathrm{II})-$ with $\mathrm{Ck}-\mathrm{SCNPs} 2$ being more efficient than Ck-SCNPs1 (or $\mathrm{CuSO}_{4}$ ) in both solvents. The presence of clusters of $\mathrm{Cu}$ ions in the case of Ck-SCNPs2 was beneficial for improving the stability and effectiveness of "clickase" SCNPs in DMSO solvent. In this sense, control of the intra-chain distribution of catalytic sites could be also a useful strategy to improve the catalytic activity of other metallo-folded SCNPs containing metal ions different from $\mathrm{Cu}$ ones.

Author Contributions: This manuscript has been written with the contribution from all authors. All authors have read and agreed to the published version of the manuscript.

Funding: This research was funded by Basque Government, grant number IT-1175-19; and MCIU / AEI / FEDER, UE, grant number PGC2018-094548-B-I00.

Acknowledgments: E.V.-S. is grateful to the Materials Physics Center-MPC for her postdoctoral grant.

Institutional Review Board Statement: Not applicable.

Informed Consent Statement: Not applicable.

Data Availability Statement: Data are available upon request.

Conflicts of Interest: The authors declare no conflict of interest.

\section{References}

1. Pomposo, J.A. (Ed.) Single-Chain Polymer Nanoparticles: Synthesis, Characterization, Simulations and Applications; Wiley-VCH: Weinheim, Germany, 2017.

2. Ruiwen, C.; Berda, E.B. 100th Anniversary of Macromolecular Science Viewpoint: Re-examining Single-Chain Nanoparticles. ACS Macro Lett. 2020, 9, 1836-1843.

3. Frisch, H.; Tuten, B.T.; Barner-Kowollik, C. Macromolecular Superstructures: A Future Beyond Single Chain Nanoparticles. Isr. J. Chem. 2020, 60, 86-99. 
4. Chen, J.; Garcia, E. S.; Zimmerman, S.C. Intramolecularly Cross-Linked Polymers: From Structure to Function with Applications as Artificial Antibodies and Artificial Enzymes. Acc. Chem. Res. 2020, 53, 1244-1256.

5. Terashima, T. Controlled Self-Assembly of Amphiphilic Random Copolymers into Folded Micelles and Nanostructure Materials. J. Oleo Sci. 2020, 69, 529-538.

6. Verde-Sesto, E.; Arbe, A.; Moreno, A.J.; Cangialosi, D.; Alegría, A.; Colmenero, J.; Pomposo, J.A. Single-chain nanoparticles: opportunities provided by internal and external confinement, Mater. Horiz. 2020, 7, 2292-2313.

7. ter Huurne, G.M.; Palmans, A.R.A.; Meijer, E.W. Supramolecular Single-Chain Polymeric Nanoparticles. CCS Chem. 2019, 1, 64-82.

8. Altintas, O.; Barner-Kowollik, C. Single-chain folding of synthetic polymers: a critical update. Macromol. Rapid Commun. 2016, 37, 29-46.

9. Hanlon, A.M.; Lyon, C.K.; Berda, E.B. What is next in single-chain nanoparticles? Macromolecules 2016, 49, 2-14.

10. Mavila, S.; Eivgi, O.; Berkovich, I.; Lemcoff, N.G. Intramolecular cross-linking methodologies for the synthesis of polymer nanoparticles. Chem. Rev. 2016, 116, 878-961.

11. Gonzalez-Burgos, M.; Latorre-Sanchez, A.; Pomposo, J.A. Advances in single chain technology. Chem. Soc. Rev. 2015, 44, 6122-6142.

12. Lyon, C.K.; Prasher, A.; Hanlon, A.M.; Tuten, B.T.; Tooley, C.A.; Frank, P.G.; Berda, E.B. A brief user's guide to single-chain nanoparticles. Polym. Chem. 2015, 6, 181-197.

13. Müge, A.; Elisa, H.; Meijer, E.W.; Palmans, A.R.A. Dynamic single chain polymeric nanoparticles: from structure to function. In Sequence-Controlled Polymers: Synthesis, Self-Assembly, and Properties; American Chemical Society: Washington, DC, USA, 2014; Volume 1170, pp. 313-325.

14. Sanchez-Sanchez, A.; Pomposo, J.A. Single-chain polymer nanoparticles via non-covalent and dynamic covalent bonds. Part. Part. Syst. Charact. 2014, 31, 11-23.

15. Sanchez-Sanchez, A.; Perez-Baena, I.; Pomposo, J.A. Advances in click chemistry for single-chain nanoparticle construction. Molecules 2013, 18, 3339-3355.

16. Altintas, O.; Barner-Kowollik, C. Single chain folding of synthetic polymers by covalent and noncovalent interactions: Current status and future perspectives. Macromol. Rapid Commun. 2012, 33, 958971.

17. Aiertza, M.; Odriozola, I.; Cabañero, G.; Grande, H.-J.; Loinaz, I. Single-chain polymer nanoparticles. Cell. Mol. Life Sci. 2012, 69, 337-346.

18. Pomposo, J.A. Bioinspired single-chain polymer nanoparticles. Polym. Int. 2014, 63, 589-592.

19. Latorre-Sanchez, A.; Pomposo, J.A. Recent bioinspired applications of single-chain nanoparticles. Polym. Int. 2016, 65, 855-860.

20. Cole, J.P.; Hanlon, A.M.; Rodriguez, K.J.; Berda, E.B. Protein-Like Structure and Activity in Synthetic Polymers. J. Polym. Sci., Part A: Polym. Chem. 2017, 55, 191-206.

21. De-La-Cuesta, J.; González, E.; Pomposo, J.A. Advances in Fluorescent Single-Chain Nanoparticles. Molecules 2017, 22, 1819.

22. Kroger, A.P.P.; Paulusse, J.M.J. Single-Chain Polymer Nanoparticles in Controlled Drug Delivery and Targeted Imaging. J. Controlled Release 2018, 286, 326-347.

23. Verde-Sesto, E.; Blazquez-Martin, A.; Pomposo, J.A. Advances in the Phototriggered Synthesis of Single-Chain Polymer Nanoparticles. Polymers 2019, 11, 1903.

24. Hoffmann, J.F.; Roos, A.H.; Schmitt, F.-J.; Hinderberger, D.; Binder, W.H. Fluorescent and water dispersible single-chain nanoparticles: core-shell structured compartmentation. Angew. Chem. Int. Ed. 2021, DOI: 10.1002/anie.202015179.

25. Rothfuss, H.; Knofel, N.D.; Roesky, P.W.; Barner-Kowollik, C. Single-Chain Nanoparticles as Catalytic Nanoreactors. J. Am. Chem. Soc. 2018, 140, 5875-5881.

26. Rubio-Cervilla, J.; Gonzalez, E.; Pomposo, J.A. Advances in Single-Chain Nanoparticles for Catalysis Applications. Nanomaterials 2017, 7, 341.

27. Pomposo, J.A.; Perez-Baena, I.; Lo Verso, F.; Moreno, A.J.; Arbe, A.; Colmenero, J. How Far Are Single-Chain Polymer Nanoparticles in Solution from the Globular State? ACS Macro Lett. 2014, 3 , 767-772.

28. Pomposo, J.A.; Moreno, A.J.; Arbe, A.; Colmenero, J. Local Domain Size in Single-Chain Polymer Nanoparticles. ACS Omega 2018, 3, 8648-8654. 
29. Perez-Baena, I.; Barroso-Bujans, F.; Gasser, U.; Arbe, A.; Moreno, A.J.; Colmenero, J.; Pomposo, J.A. Endowing Single-Chain Polymer Nanoparticles with Enzyme-Mimetic Activity. ACS Macro Lett. 2013, 2, 775-779.

30. Mavila, S.; Rozenberg, I.; Lemcoff, N.G. A general approach to mono- and bimetallic organometallic nanoparticles. Chem. Sci. 2014, 5, 4196-4203.

31. Sanchez-Sanchez, A.; Arbe, A.; Colmenero, J.; Pomposo, J.A. Metallo-Folded Single-Chain Nanoparticles with Catalytic Selectivity. ACS Macro Lett. 2014, 3, 439-443.

32. Willenbacher, J.; Altintas, O.; Trouillet, V.; Knöfel, N.; Monteiro, M.J.; Roesky, P.W.; BarnerKowollik, C. Pd-complex driven formation of single-chain nanoparticles. Polym. Chem. 2015, 6, 43584365.

33. Knöfel, N.D.; Rothfuss, H.; Willenbacher, J.; Barner-Kowollik, C.; Roesky, P.W. Platinum(II)Crosslinked Single-Chain Nanoparticles: An Approach towards Recyclable Homogeneous Catalysts. Angew. Chem., Int. Ed. 2017, 56, 4950-4954.

34. Knöfel, N.D.; Rothfuss, H.; Tzvelkova, P.; Kulendran, B.; Barner-Kowollik, C.; Roesky, P.W. Heterobimetallic $\mathrm{Eu}(\mathrm{III}) / \mathrm{Pt}(\mathrm{II})$ single-chain nanoparticles: a path to enlighten catalytic reactions. Chem. Sci. 2020, 11, 10331-10336.

35. Thanneeru, S.; Nganga, J.K.; Amin, A.S.; Liu, B.; Jin, L.; Angeles-Boza, A.M.; He, J. “Enzymatic” Photoreduction of Carbon Dioxide using Polymeric Metallofoldamers Containing Nickel-Thiolate Cofactors. ChemCatChem 2017, 9, 1157-1162.

36. Freytag, K.; Säfken, S.; Wolter, K.; Namyslo, J.C.; Hübner, E.G. Hybrid single-chain nanoparticles via the metal induced crosslinking of N-donor functionalized polymer chains. Polym. Chem. 2017, 8 , 7546-7558.

37. Rumyantsev, M.; Rumyantsev, S. Combining advantages of homogeneous organocatalysis and heterogeneous catalysis with thermosensitive single-chain nanoparticles in a representative tetrahydropyranilation of alcohols. Polymer 2018, 136, 101-108.

38. Garmendia, S.; Dove, A.P.; Taton, D.; O’Reilly, R.K. Self-catalysed folding of single chain nanoparticles (SCNPs) by NHC-mediated intramolecular benzoin condensation. Polym. Chem. 2019, 10, 2282-2289.

39. Garmendia, S.; Lawrenson, S.B.; Arno, M.C.; O’Reilly, R.K.; Taton, D.; Dove, A.P. Catalytically Active N-Heterocyclic Carbene Release from Single-Chain Nanoparticles Following a ThermolysisDriven Unfolding Strategy. Macromol. Rapid Commun. 2019, 40, 1900071.

40. Zeng, R.; Chen, L.; Yan, Q. CO2-Folded Single-Chain Nanoparticles as Recyclable, Improved Carboxylase Mimics. Angew. Chem. Int. Ed. 2020, 59, 18418-18422.

41. Piane, J.J.; Chamberlain, L.E.; Huss, S.; Alameda, L.T.; Hoover, A.C.; Elacqua, E. Organic Photoredox-Catalyzed Cycloadditions Under Single-Chain Polymer Confinement. ACS Catal. 2020, 10, 13251-13256.

42. Hu, Z.-Y.; Pu, H.-T.; Wu, J.-G. Platinum Atoms Dispersed in Single-chain Polymer Nanoparticles. Chin. J. Polym. Sci. 2020. DOI: 10.1007/s10118-021-2499-x.

43. Hu, Z.-Y.; Pu, H.-T. Single-chain polymer nanoparticles carried cuprous catalysts. Eur. Polym. J. 2021, 143, 110194.

44. Terashima, T.; Mes, T.; De Greef, T.F.A.; Gillissen, M.A.J.; Besenius, P.; Palmans, A.R.A.; Meijer, E.W. Single-Chain Folding of Polymers for Catalytic Systems in Water. J. Am. Chem. Soc. 2011, 133, 4742-4745.

45. Artar, M.; Souren, E.R.J.; Terashima, T.; Meijer, E.W.; Palmans, A.R.A. Single Chain Polymeric Nanoparticles as Selective Hydrophobic Reaction Spaces in Water. ACS Macro Lett. 2015, 4, 10991103.

46. Huerta, E.; Stals, P.J.M.; Meijer, E.W.; Palmans, A.R.A. Consequences of Folding a Water-Soluble Polymer Around an Organocatalyst. Angew. Chem. Int. Ed. 2013, 52, 2906-2910.

47. Huerta, E.; van Genabeek, B.; Stals, P.J.M.; Meijer, E.W.; Palmans, A.R.A. A Modular Approach to Introduce Function into Single-Chain Polymeric Nanoparticles. Macromol. Rapid Commun. 2014, 35, 1320-1325.

48. Liu, Y.; Pauloehrl, T.; Presolski, S.I.; Albertazzi, L.; Palmans, A.R.A.; Meijer, E.W. Modular Synthetic Platform for the Construction of Functional Single-Chain Polymeric Nanoparticles: From Aqueous Catalysis to Photosensitization. J. Am. Chem. Soc. 2015, 137, 13096-13105. 
49. Liu, Y.; Pujals, S.; Stals, P.J.M.; Paulöhrl, T.; Presolski, S.I.; Meijer, E.W.; Albertazzi, L.; Palmans, A.R.A. Catalytically Active Single-Chain Polymeric Nanoparticles: Exploring Their Functions in Complex Biological Media. J. Am. Chem. Soc. 2018, 140, 3423-3433.

50. Sanchez-Sanchez, A.; Arbe, A.; Kohlbrecher, J.; Colmenero, J.; Pomposo, J.A. Efficient Synthesis of Single-Chain Globules Mimicking the Morphology and Polymerase Activity of Metalloenzymes. Macromol. Rapid Commun. 2015, 36, 1592-1597.

51. De-La-Cuesta, J.; Asenjo-Sanz, I.; Latorre-Sanchez, A.; Gonzalez, E.; Martinez-Tong, D.E.; Pomposo, J.A. Enzyme-mimetic synthesis of PEDOT from self-folded iron-containing single-chain nanoparticles. Eur. Polym. J. 2018, 109, 447-452.

52. Bai, Y.; Feng, X.; Xing, H.; Xu, Y.; Kim, B.K.; Baig, N.; Zhou, T.; Gewirth, A.A.; Lu, Y.; Oldfield, E.; Zimmerman, S.C. A Highly Efficient Single-Chain Metal-Organic Nanoparticle Catalyst for Alkyne-Azide "Click" Reactions in Water and in Cells. J. Am. Chem. Soc. 2016, 138, 11077-11080.

53. Chen, J.; Wang, J.; Bai, Y.; Li, K.; Garcia, E.S.; Ferguson, A.L.; Zimmerman, S.C. Enzyme-like Click Catalysis by a Copper-Containing Single-Chain Nanoparticle. J. Am. Chem. Soc. 2018, 140, 1369513702.

54. Chen, J.; Wang, J.; Bai, Y.; Li, K.; Wang, Y.; Gruebele, M.; Ferguson, A.L.; Zimmerman, S.C. Polymeric "Clickase" Accelerates the Copper Click Reaction of Small Molecules, Proteins, and Cells. J. Am. Chem. Soc. 2019, 141, 9693-9700.

55. Chen, J.; Li, K.; Bonson, S.E.; Zimmerman, S.C. A Bioorthogonal Small Molecule Selective Polymeric "Clickase". J. Am. Chem. Soc. 2020, 142, 13966-13973.

56. Chen, J.; Li, K.; Shon, J.S.L.; Zimmerman, S.C. Single-Chain Nanoparticle Delivers a Partner Enzyme for Concurrent and Tandem Catalysis in Cells. J. Am. Chem. Soc. 2020, 142, 4565-4569.

57. Thanneeru, S.; Duay, S.S.; Jin, L.; Fu, Y.; Angeles-Boza, A.M.; He, J. Single Chain Polymeric Nanoparticles to Promote Selective Hydroxylation Reactions of Phenol Catalyzed by Copper. ACS Macro Lett. 2017, 6, 652-656.

58. Thanneeru, S.; Milazzo, N.; Lopes, A.; Wei, Z.; Angeles-Boza, A.M.; He, J. Synthetic Polymers To Promote Cooperative $\mathrm{Cu}$ Activity for $\mathrm{O}_{2}$ Activation: Poly vs Mono. J. Am. Chem. Soc. 2019, 141, 42524256.

59. Zhang, Y.; Tan, R.; Gao, M.; Hao, P.; Yin, D. Bio-inspired single-chain polymeric nanoparticles containing a chiral salen TiIV complex for highly enantioselective sulfoxidation in water. Green Chem. 2017, 19, 1182-1193.

60. Zhang, Y.; Wang, W.; Fu, W.; Zhang, M.; Tang, Z.; Tan, R.; Yin, D. Titanium(IV)-folded singlechain polymeric nanoparticles as artificial metalloenzyme for asymmetric sulfoxidation in water. Chem. Commun. 2018, 54, 9430-9433.

61. Lambert, R.; Wirotius, A.L.; Taton, D. Intramolecular Quaternization as Folding Strategy for the Synthesis of Catalytically Active Imidazolium-Based Single Chain Nanoparticles. ACS Macro Lett. 2017, 6, 489-494.

62. Garmendia, S.; Dove, A.P.; Taton, D.; O'Reilly, R.K. Reversible ionically-crosslinked single chain nanoparticles as bioinspired and recyclable nanoreactors for $\mathrm{N}$-heterocyclic carbene organocatalysis. Polym. Chem. 2018, 9, 5286-5294.

63. Lambert, R.; Wirotius, A.L.; Garmendia, S.; Berto, P.; Vignolle, J.; Taton, D. Pd(II)-NHC coordination-driven formation of water-soluble catalytically active single chain nanoparticles. Polym. Chem. 2018, 9, 3199-3204.

64. Basasoro, S.; Gonzalez-Burgos, M.; Moreno, A.J.; Lo Verso, F.; Arbe, A.; Colmenero, J.; Pomposo, J.A. A Solvent-Based Strategy for Tuning the Internal Structure of Metallo-Folded Single-Chain Nanoparticles. Macromol. Rapid Commun. 2016, 37, 1060-1065.

65. Chang, K.-C.; Su, I.-H.; Senthilvelan, A.; Chung, W.-S. Triazole-Modified Calix[4]crown as a Novel Fluorescent On-Off Switchable Chemosensor. Org. Lett. 2007, 9, 3363-3366.

66. Xie, F.; Sivakumar, K.; Zeng, Q.; Bruckman, M.A.; Hodges, B.; Wang, Q. A fluorogenic 'click' reaction of azidoanthracene derivatives. Tetrahedron 2008, 64, 2906-2914.

67. Wu, Y.; Huang, Z.; Luo, Y.; Liu, D.; Deng, Y.; Yi, H.; Lee, J.F.; Pao, C.W.; Chen, J.L.; Lei, A. X-ray Absorption and Electron Paramagnetic Resonance Guided Discovery of the Cu-Catalyzed Synthesis of Multiaryl-Substituted Furans from Aryl Styrene and Ketones Using DMSO as the Oxidant. Org. Lett. 2017, 19, 2330-2333. 
